\title{
CONTRIBUIÇÕES DE ANDREW MAUNSELL À CATALOGAÇÃO: UMA BREVE NARRATIVA DO CABEÇALHO "BÍBLIA"
}

\author{
CONTRIBUCIONES DE ANDREW MAUNSELL A LA \\ CATALOGACIÓN: NARRATIVA BREVE DEL \\ ENCABEZAMIENTO "BIBLIA"
}

Marcelo Nair dos Santosa

\begin{abstract}
RESUMO
Introdução: As contribuições de Andrew Maunsell influenciaram amplamente a concepção de pontos de acesso às entradas dos catálogos das bibliotecas no transcurso dos anos, uma vez que muitas delas ainda estão em catálogos e nas regras de catalogação anglo-americanas, como é o caso do cabeçalho titular "Bíblia", empregado para reunir as entradas dessa obra no catálogo. Objetivo: Traçar o contexto histórico do livreiro londrino, com o fim de conhecer como ele idealizou o cabeçalho e como o empregou em seu tempo, e examinar historicamente como o cabeçalho "Bíblia" se efetivou nos catálogos e nas regras catalográficas posteriores, de modo a investigar como isso foi apropriado pela Catalogação para representar a obra sagrada. Metodologia: Pesquisa bibliográfica e documental. Resultados: A catalogação foi incorporando subcabeçalhos alusivos aos atributos da obra sagrada, os quais influenciaram a disposição das entradas dessa obra em dimensão vertical e horizontal. Ademais, a partir do cabeçalho "Bíblia", a catalogação pôde desenvolver o fundamento e os princípios do título uniforme para representar outras obras. Isso nem sempre se deu coerentemente porque o título uniforme foi desestruturado por subcabeçalhos estranhos à representação da obra sagrada. Ante a essa situação, modelos bibliográficos da catalogação e a normativa "Resource Description and Access" (RDA) foram concebidos para reduzir as impropriedades da catalogação, como as existentes nos subcabeçalhos dessa obra. Conclusões: A normativa RDA oferece meios de representar singularmente a Bíblia nos pontos de acesso dos registros bibliográficos alusivos às publicações dessa obra, a despeito das ressalvas contornáveis que possam haver. Assim, Maunsell plantou essa e outras práticas catalográficas que foram regadas por aqueles que desenvolveram a catalogação no transcurso dos anos.
\end{abstract}

a Doutorando em Ciência da Informação, do Programa de Pós-Graduação da Universidade Federal de Minas Gerais (PPGCI-UFMG). Professor do Curso de Biblioteconomia da Universidade Federal do Espírito Santo (UFES). E-mail: marcelonair@hotmail.com 
Descritores: Maunsell, Andrew, ?-1596. Entradas. Regras de catalogação.

\section{INTRODUÇÃO}

Os acontecimentos do século XV e XVI influenciaram substancialmente a história da humanidade, pois foram caracterizados por movimentos políticos, sociais, tecnológicos e científicos, os quais, de alguma maneira, influenciaram as práticas bibliográficas e catalográficas desenvolvidas posteriormente. A mudança mais notável para as atividades bibliográficas se deu pela inovação dos meios tipográficos realizada por Johannes Gutenberg, com a consequente difusão do livro impresso em tipografia, daí, nos termos da atividade em questão, os catálogos começaram a ser publicados de modo impresso, em formato de livro.

É por esse contexto que se começou a desenvolver e experimentar dispositivos úteis para o catálogo, os quais transformaram-no em algo além de listas inventariantes de livros, propriedade que o caracterizou desde as primeiras bibliotecas da Antiguidade. No âmbito das bibliotecas, a catalogação desse período não teria muito a dar se dependesse unicamente dos bibliotecários e de seus catálogos, pois os avanços desse processo devem muito à atividade bibliográfica, especialmente à sua parte que trata da relação sistemática de livros em catálogos, a qual está ligada às origens históricas da Bibliografia.

Não se trata em absoluto de negar que não houve avanços no âmbito das bibliotecas. Veja-se, por exemplo, que as primeiras tentativas de uso de remissivas, embora em estágio rudimentar, se deram no catálogo compilado entre 1410 e 1412 por Amplonius Ratnick de Berka (STROUT, 1956, p. 262) e no Catálogo da Biblioteca de St. Augustine, Canterbury (Reino Unido), este em estágio mais desenvolvido (NORRIS, 1939, p. 115). Contudo, nesse período, cabe destacar que as contribuições mais efetivas são provenientes da atividade bibliográfica, conforme a literatura apropriada 
menciona correntemente, especialmente aquela voltada para a história da Catalogação' ${ }^{1}$.

Cabe ressalvar que, embora certos desbravadores da bibliografia Conrad Gesner, FlorianusTreflerus e Andrew Maunsell - sejam evocados como a origem de práticas catalográficas, a literatura sobre história da catalogação menciona tão somente as contribuições dadas por eles à catalogação, sem tecer detalhes ou evidências dos trabalhos que eles realizaram. Nesse aspecto, faltaria examinar como isso se deu de fato, por isso, dentre os pioneiros da atividade bibliográfica mencionados acima, o escopo deste trabalho volta-se para Andrew Maunsell, livreiro e impressor londrino, o qual deu contribuições significativas à Catalogação que perduram ainda hoje nas regras regulatórias da catalogação.

Em face disso, o objetivo deste trabalho é evidenciar as contribuições de Andrew Maunsell e como uma delas se assentou nas regras catalográficas da vertente anglo-americana. Para tanto, nas seções subsequentes, convém traçar brevemente o contexto histórico desse pioneiro da bibliografia, de modo a conhecer as contribuições que ele efetivou em seu tempo no tocante à catalogação, e examinar historicamente como uma delas se efetivou nos catálogos e nas regras catalográficas posteriores, de modo a investigar como ela foi apropriada pela Catalogação. Desse modo, ao final do artigo, tem-se a intenção de tecer algumas considerações sobre como a contribuição em questão foi desenvolvida em catalogação no transcurso dos anos.

\section{ANDREW MAUNSELL E SEU CATÁLOGO}

As informações sobre Maunsell são poucas porque muitas delas foram perdidas, mas se sabe que ele vendia produtos têxteis antes de se tornar livreiro na década de 1570. De acordo com Growoll e Eames (1903, p. 25),

\footnotetext{
'Grafamos 'Catalogação' como substantivo próprio para designá-la enquanto campo de estudo teórico-metodológico, emcontrapontoao substantivo comumdesignador dos processos de produção de descrição bibliográfica e pontos de acesso.
}

Inf. Inf., Londrina, v. 23, n. 2, p. 152 - 180, maio/ago. 2018. http://www.uel.br/revistas/informacao/ 
também não há registros de que ele tenha impresso algo antes de 1576, dado que ele foi mais livreiro do que impressor. Mesmo assim e a despeito de ele ter licença para imprimir vários livros, o seu catálogo foi o mais notável que ele imprimiu (GROWOLL; EAMES, 1903, p. 25).

Suas atividades se deram num mercado livreiro em formação ainda por maturar, no qual o impressor custeava suas próprias publicações e as comercializava no mercado londrino ou em feiras de livros realizadas em outras partes da Inglaterra. À medida que o tempo passava, a produção livreira comercializada aumentou, levando a certos questionamentos como os de Rogers (apud GROWOLL; EAMES, 1903, p. 22): como distribuir as várias obras de um autor ou como o livreiro alcançaria seu o leitor? Nesse contexto, havia a constatação de que negociante e comprador precisavam conhecer melhor um ao outro. Além disso, naquele tempo, a impressão de cada publicação era custosa, levando impressores e livreiros a buscar meios de dividir riscos e lucros de seu negócio, compartilhando proporcionalmente os custos de produção de uma publicação, parceria pela qual foi possível variar as publicações impressas. Em face de tudo isso, já se percebia que um catálogo de vendas era uma necessidade premente (GROWOLL; EAMES, 1903, p. 23).

É nesse contexto, pois, que Andrew Maunsell compilou o primeiro catálogo de alcance nacional, primariamente destinado ao mercado livreiro inglês, o qual continha o nome de vários autores e títulos (GROWOLL; EAMES, 1903, p. 26). Nesse sentido, o valor e o método do catálogo do londrino são expressos na dedicatória que ele escreveu na introdução da primeira parte do seu "Catalogue of English Printed Books" (MAUNSELL, 1595). Para ele, o livreiro deveria ter seu catálogo do mesmo modo que o "farmacêutico sua farmacopeia, ou o professor, o seu dicionário" (MAUNSELL, 1595, tradução nossa). Com esse direcionamento em mente, Maunsell expressou o que o leitor podia esperar de seu trabalho: este seria capaz de se lembrar de livros esquecidos e teria condições de ter conhecimento de livros em sua língua nativa.

Maunsell tinha o propósito de publicar o seu catálogo em três partes, sendo que a primeira, publicada em 1595, registrou 2639 livros e sermões 
dedicados a temas sobre divindade (GROWOLL; EAMES, 1903, p. 30-31). Ainda nesse ano, a segunda parte do catálogo foi publicada, dedicada a ciências matemáticas (aritmética, geometria, astronomia, astrologia e música), arte da guerra e navegação, com mais de 320 registros de livros. A terceira parte - humanidade, a qual reunia temas como: língua, gramática, lógica, retórica, lei, história, poesia, política, etc. - não foi publicada devido à morte do londrino em 1596.

Por seu trabalho, qualificado como estimulante por Hanson e Daily (1970, p. 254), o valor das contribuições de Maunsell foi reconhecido por estudiosos depois dele, em especial por aqueles que tratam da história da catalogação. Norris (1939, p. 140, tradução nossa), por exemplo, afirmou que "se ele tivesse vivido mais e fosse um bibliotecário em vez de livreiro, poderia ter preparado o nosso primeiro código de regras." A despeito da declaração dessa estudiosa, conhecida por exemplificar os catálogos e os métodos catalográficos do século XII ao XIX, ela não ofereceu muitas evidências do catálogo do londrino, limitando-se a expor o valor de seu trabalho, o que não dista daquilo que outros estudiosos declararam a respeito de Maunsell. Por isso, mais que reconhecer a sua obra, cumpre investigar e compreender com exatidão como se deram as contribuições do londrino para a catalogação, nos termos de seu catálogo.

Antes disso, porém, convém abrir um parêntesis para esclarecer o entendimento a respeito de certos termos mencionados neste texto. O primeiro deles diz respeito a entrada, termo entendido como um registro de uma publicação em um catálogo, o qual compreende um conjunto de atributos tomados da mesma. A mesma equivale a registro bibliográfico, este último um termo cunhado recentemente, fruto da incorporação de novas tecnologias no âmbito da catalogação, sinaliza Rios Hilário (2003). De mais a mais, tal equivalência é sustentada pelo entendimento de ser a entrada, segundo Reitz (2017, tradução nossa), "um registro único no catálogo de biblioteca que representa um item contido em sua coleção", correspondente ao registro em base de dados bibliográfica representativo de um dado ente bibliográfico, podendo se referir a uma referência de bibliografia. 
No âmbito das entradas, há que ainda considerar o modo pelo qual elas são pesquisadas por aqueles que consultam catálogos. $O$ exame das entradas e o acesso a elas se fazem por intermédio de um ou mais vocábulos pelos quais as mesmas são organizadas no catálogo, os quais, em conjunto, são denominados de ponto de acesso. De outro modo, o ponto de acesso é composto de palavras que proporcionam o acesso aos registros ou as entradas com informações representativas de uma publicação, do qual é possível estabelecer índices em catálogo ou em base de dados. Anteriormente, o ponto de acesso era referido por cabeçalho - denominado assim por estar localizado na parte superior da entrada. Por vezes, o cabeçalho era composto por dois ou mais segmentos, em que o primeiro era denominado de cabeçalho principal; os subsequentes, de subcabeçalhos que serviam para delimitar o primeiro segmento.

Feitas essas considerações, podemos retornar ao catálogo de Maunsell, o qual, segundo Malclès (1961), foi inspirado de métodos e de princípios já aplicados na Alemanha por Georg Willer, pelos quais o londrino pode conceber as entradas em seu "Catalogue...". Neste, as entradas representativas das publicações foram ordenadas alfabeticamente de dois modos: (1) entradas ordenadas concomitantemente com assuntos; (2) entradas dispostas sob os assuntos ou sob os autores.

No primeiro modo, a ordenação alfabética foi feita em função da primeira palavra grafada com itálico, a qual funcionava como ponto de acesso à entrada, seja tal palavra: assunto, autor ou título, neste último, se a obra fosse publicada anonimamente sem autoria evidente. Em se tratando de assunto, o mesmo era inscrito só como cabeçalho no qual as entradas representativas de publicações do assunto em questão eram dispostas; nos demais casos, o ponto de acesso de autor ou de título era marcado com itálico nas próprias entradas. Com esse modo, $\mathrm{o}$ ato de percorrer alfabeticamente as entradas era difícil de realizar, como se pode notar nos destaques em negrito deste extrato da parte 2 do catálogo do londrino. 
Figura 1: Entradasdo "Catalogue of English Printed Books" (1595)

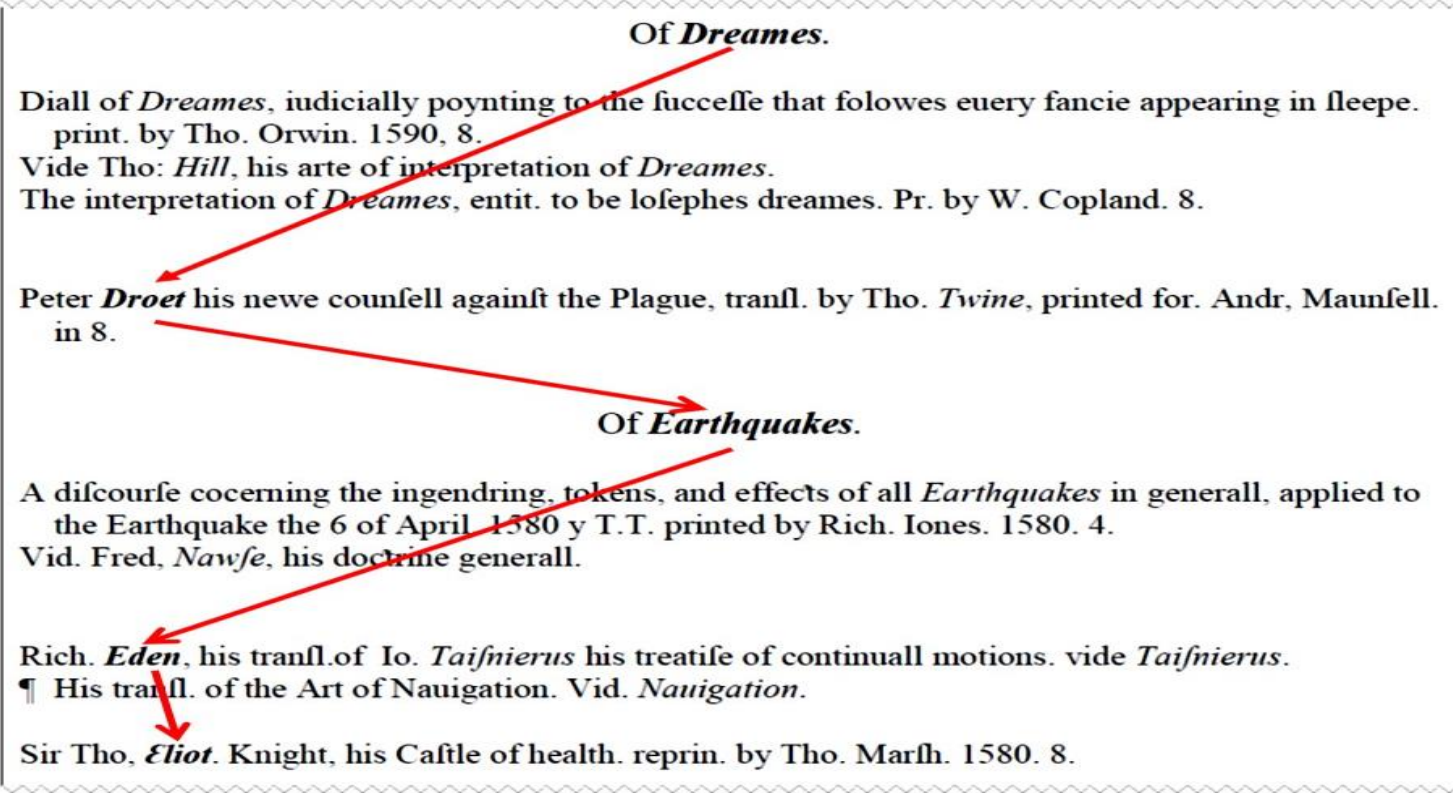

Fonte: Extrato adaptado de Maunsell (1595, pt. 2, p. 8).

Nota: Os negritos e as setas indicam as palavras empregadas para ordenar alfabeticamente as entradas e os assuntos do catálogo de Maunsell.

No segundo modo, entradas dispostas sob os assuntos ou sob os autores no catálogo, a ordenação delas variou conforme o assunto ou a produção literária do autor. Neste, a ordenação das entradas de duas ou mais publicações de um autor era feita sob a primeira entrada de sua autoria, sendo as demais listadas subsequentemente precedidas pelo símbolo " $\mathrm{T}$ ", como se observa no exemplo anterior. Por sua parte, as entradas nos assuntos eram ordenadas alfabeticamente pelo nome do autor e do título das publicações, embora nem sempre tal disposição tenha se efetivado estritamente, pois é possível encontrar incoerências dessa ordenação pelo catálogo de Maunsell.

Ademais, esse procedimento variou de acordo com o assunto, como se pode notar nas entradas sob o assunto "Sermões", as quais foram dispostas em seções divididas por letras maiúsculas. Com isso, as entradas completas dos sermões de um dado autor - lohnlewell, citado pelo próprio londrino - não foram posicionados junto com as obras daquele escritor na letra "l" do catálogo. No seu lugar havia remissiva² que direcionava o leitor para a seção "l" sob

\footnotetext{
${ }^{2}$ Remissiva é dispositivo essencial para manusear catálogos, pois remete o usuário para outros pontos do mesmo, com o fim de ampliar ou encaminar sua pesquisa documental.
}

Inf. Inf., Londrina, v. 23, n. 2, p. $152-180$, maio/ago. 2018 http://www.uel.br/revistas/informacao/ 
"Sermões", onde a entrada completa de um dos Sermões escritos por lewell seria encontrada.

Por esse arranjo, o catálogo de Maunsell caracterizou-se como um índice de assuntos, de autores e de títulos - como que um arranjo dicionário. A despeito disso, López Guillamón (2011, p. 200, tradução nossa) afirma que, embora intitulada como catálogo, sua obra "é uma bibliografia em sentido disciplinar convencional, na qual se mostra toda a produção impressa de um país."

Seja como for, as contribuições de Maunsell presentes em sua obra foram apropriadas posteriormente pela catalogação e dizem respeito ao modo de constituir o ponto de acesso às entradas, pelo qual estas são pesquisadas por aqueles que consultam o catálogo. Dentre as contribuições, pomos em evidência a constituição do ponto de acesso às entradas do catálogo: (1) pelo sobrenome do autor da publicação; (2) por um cabeçalho titular de função agregadora das publicações da ou sobre a Bíblia; (3) pelo título de publicações sem autoria evidente; (4) pelo sobrenome do tradutor em publicações traduzidas. Decerto, há outras contribuições levadas a cabo pelo londrino em seu catálogo, como a inclusão em suas entradas de informações sobre impressor, para quem se imprimiu, de data de publicação e do tipo de formato das publicações.

Para Strout, "estes foram avanços radicais e repentinos no desenvolvimento da catalogação, e não podemos deixar de notar que eles vieram do livreiro e não do bibliotecário, algo que não é desconhecido em nosso próprio tempo e em nosso próprio país." (STROUT, 1956, p. 264). Assim, essa declaração de Strout, citada recorrentemente por autores que tratam da história da catalogação, indica que as atuais práticas catalográficas herdeiras das contribuições enumeradas acima têm relação direta de influência com aquilo que Maunsell realizou em sua obra.

Dentre as contribuições, convém destacar uma delas, a qual será examinada adiante com mais atenção: o cabeçalho titular com função agregadora das publicações da ou sobre a Bíblia. Para o caso em questão, as entradas representativas das publicações de ou sobre Bíblia no catálogo de 
Maunsell foram ordenadas de acordo com a ordem dos livros nesta obra (Gênesis, Êxodo, Levítico, Deuteronômio e assim por diante). Desse modo, no catálogo do londrino, os livros bíblicos deveriam ser procurados sob o cabeçalho "Bíblia", inclusive as entradas representativas de publicações com comentários sobre a obra completa ou suas partes, conforme ele expressou na parte introdutória de seu catalogo (MAUNSELL, 1595). Veja-se este extrato do seu catálogo.

Figura 2: Entradas sob o cabeçalho Bíblia no "Catalogue of English Printed Books" (1595)

12

1. Chronicles.

Arthington on the 28 , ver. 9.

2. Chronicles.

fillthis Ser.20. ver, a:

$$
\text { Ezra. }
$$

Duktor Jemes Ser , 4. ver. $1: 2.3^{\circ}$ Willi. Chwbs Ser.4. ver. $2.2 \cdot 3^{\circ}$

\section{Nebemiab.}

Bible.

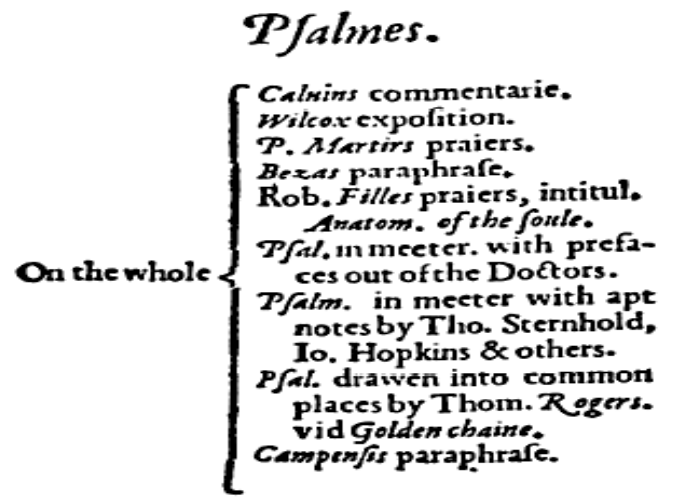

Fonte: Maunsell (1595, pt. 1, p. 12)

Por esse modo, a prática de reunir entradas sobre o cabeçalho titular de uma dada obra - versões e traduções da Bíblia - é precursora do título uniforme, termo cunhado pela catalogação na década de 1940, e Maunsell foi o primeiro a estabelecer expressamente essa prática:

A primeira expressão da ideia de reunir unidades literárias [obras] sob um único cabeçalho pode ser vista em 1595 em Andrew Maunsell, no seu Catalogue of English Printed Books. [...], embora não muito exemplo de sua aceitação pela comunidade de catalogação possa ser rastreado até 1674." (BISWAS; RATH, 2014, p. 08, tradução nossa).

Neste momento, convém esclarecer que 'unidade literária' é um termo introduzido por Julia Pettee em artigo publicado em 1936, segundo o qual "o livro à mão não é considerado como um item único, mas como representante de uma unidade literária." (PETTEE, 1936, p. 270, tradução nossa).

Inf. Inf., Londrina, v. 23, n. 2, p. $152-180$, maio/ago. 2018 http://www.uel.br/revistas/informacao/ 
Posteriormente, Eva Verona (1959, p. 80) refinou o entendimento de Pettee e evidenciou o contraponto da unidade literária, isto é, a unidade bibliográfica que correspondente a um livro específico, conforme edição ou tradução de uma dada obra. Nesses termos, temos o entendimento de que a unidade literária corresponde à entidade obra enquanto fruto da criação intelectual ou artística diferenciada de um ou mais indivíduos, cuja identidade se mantém na diversidade de unidades bibliográficas (edições, versões, revisões, traduções e outras) que incorporam a mesma.

Em face da prática de Maunsell de agrupar entradas de ou sobre a Bíblia e suas partes por intermédio de um cabeçalho titular alusivo a essa obra, é possível investigar como essa contribuição foi incorporada às regras catalográficas no transcurso dos anos. Com efeito, dela emana a progressão da noção de unidades literárias, que, nos termos do título uniforme da catalogação, viabiliza o agrupamento das entradas representativas das publicações de uma dada obra em um catálogo, conforme se aborda na sequência.

\section{A APROPRIAÇÃO DO CABEÇALHO TITULAR "BíBLIA" PELA CATALOGAÇÃO NO TRANSCURSO DOS ANOS}

Tendo a finalidade de investigar a contribuição de Maunsell no tocante ao cabeçalho titular "Bíblia", convém abordá-la segundo os momentos históricos significativos indicados pela literatura sobre catalogação angloamericana, dentre os quais pomos em evidência: os catálogos da Biblioteca Bodleiana, as "91 Regras" de Panizzi, as regras concebidas por Jewett, as regras de Cutter, os códigos de catalogação da ALA com suas versões, a Conferência de Paris de 1961, o "Anglo-American Cataloging Rules" (AACR) com suas edições e revisões e a recente normativa "Resource Description and Access" (RDA).

Antes de avançar, vale considerar que, segundo Strout (1956, p. 275), a despeito do caminho traçado por Maunsell, a adoção de suas ideias se deu tardiamente, pois suas contribuições demoraram a ser apreendida pela maioria dos bibliotecários. A despeito disso, vale lembrar que não se identificou na 
literatura pertinente qualquer declaração textual que confirme que tal apreensão tenha se dado deliberadamente antes do século $X X$, dado que 0 reconhecimento das contribuições de Maunsell só começa a ser observado nos estudos catalográficos realizados a partir do século XX. Por isso, é factível que tal apropriação tenha se dado por aproximação, por coocorrência, por similaridade ou mesmo por influência direta ou não daquilo que o londrino concebera. Seja como for, isso não invalida o fato de que autores da catalogação apontam que certas práticas da catalogação têm origem no trabalho do livreiro inglês.

Tendo isso em conta, o emprego do cabeçalho titular "Bíblia" ressurgiu no catálogo da Biblioteca Bodleiana (Universidade de Oxford, Inglaterra) do século XVIII, no qual ele foi adotado para reunir as publicações dessa unidade literária. Isso se deu expressamente no catálogo publicado em 1738, o qual estabeleceu divisões do termo "BIBLIA SACRA" de acordo com a versão linguística ou vernacular desse livro sagrado, sem considerar, contudo, os livros contidos nela, como fez o londrino, em 1595. O esquema de ordenação das entradas das publicações relativas à Bíblia e suas partes no catálogo em questão pode ser visto a seguir.

Figura 3: Esquema de ordenação das entradas sob "Bíblia" em catálogo da Biblioteca Blodeiana (1738)

\begin{tabular}{|l|l|}
\hline Bíblia completa & $\begin{array}{l}\text { BIBLIA SACRA } \\
\text { - HEBRAICA, POLYGLOTTA, \&C }\end{array}$ \\
\cline { 2 - 3 } & BIBL. S. S. VERSIONES, \\
& - GR/ECFE. \\
& - LATINAFE. \\
& - ANGLICAN/E. \\
& ARMENIEE. \\
& BELGICÆE. \\
\hline Partes bíblicas & sob cabeçalhos próprios dos livros bíblicos \\
\hline
\end{tabular}

Fonte: "CatalogusImpressorumLibrorumBibliothecaeBodleianae In Academiaoxoniensi. Oxonil” (BODLEIAN LIBRARY, 1738).

Note-se que as entradas das versões bíblicas gregas e latinas aparentemente pela importância de serem as línguas originais do livro antecedem as outras versões, estas últimas ordenadas alfabeticamente pela língua. O catálogo posterior, datado de 1843, acrescentou o cabeçalho 
"BibleSociety" antes de "Biblia Sacra" e incluiu mais versões linguísticas, o que parece ser apenas uma atualização que não alterou substancialmente aquilo que fora definido no catálogo de 1738.

Já no século XIX, a partir daquilo que examinou em diversas bibliotecas, Antônio Panizzi (1797-1879), italiano refugiado nas llhas Britânicas e contratado para trabalhar na biblioteca do Museu Britânico, percebeu que uma ou mais publicações podiam ser edição, tradução ou comentário de uma obra determinada. Ele lutou para que tais aspectos fossem contemplados nas "91 Regras", como ficaram conhecidas as "Rules for the Compilation of the Catalogue", concebidas por ele e por sua equipe para constituir o "Catalogue of Printed Books In the British Museum" (1841).

No tocante ao cabeçalho "Bíblia", Panizzi proveu em suas regras meios de reunir as edições, traduções e partes do livro sagrado no catálogo. Isso se deu por intermédio de orientações dadas na regra LXXIX de seu código, pela qual as entradas de publicações do Velho e do Novo Testamento dessa obra, inclusive suas partes (nome dos livros ou de grupos de livros), deveriam ser catalogadas sob o cabeçalho geral "Bíblia" (BRITISH MUSEUM, 1841 , p. viii), de sorte que as partes se afiguravam como subcabeçalhos de "Bíblia".

Para tal inclusão, essa regra foi dividida em dez seções com orientações especificas de como efetivar os cabeçalhos, pelos quais as entradas das edições, das traduções e das partes dessa obra sagrada poderiam ser ordenadas no catálogo, como se pode notar no esquema a seguir.

Figura 4: Esquema de ordenação das entradas sob "Bíblia" no "Catalogue of Printed Books In the British Museum" (1841)

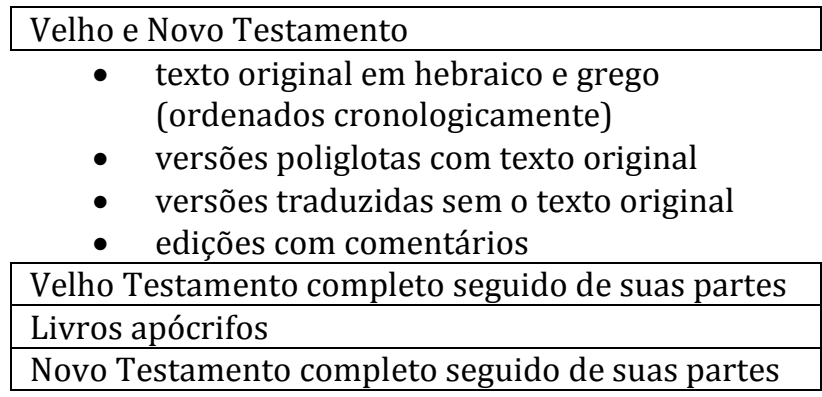

Fonte: British Museum (1841, p. viii-ix). 
Não se identificou, porém, qualquer exemplo de entradas em catálogos sob o termo "Bíblia", uma vez que, no "Catalogue of Printed Books In the British Museum", só a letra A foi impressa. A despeito disso, é possível encontrar sob o catálogo publicado remissivas que oferecem indícios de como isso se deu nas entradas da biblioteca do Museu Britânico, as quais podemos exemplificar deste modo: "BIBLE-Esther" ou "BIBLE. Heb. O. T. MinorProphets." (BRITISH MUSEUM, 1841).

Assim, Panizzi foi o primeiro a fixar expressamente tal orientação em regras catalográficas, apropriando-se da ideia básica de Andrew Maunsell e desdobrando aquilo que se fizera nos catálogos da Biblioteca Bodleiana. Daí, serem as seções da regra LXXIX das "91 Regras" legados da catalogação, pois acabaram por estabelecer "[...] o padrão para toda a catalogação moderna da Bíblia, bem como outras escrituras sagradas", (LEHNUS,1972, p. 32, tradução nossa), ao mesmo tempo que é, segundo Pettee (1936, p. 281, tradução nossa), "[...] a primeira regra formulada para o tipo de literatura conhecida agora como clássicos anônimos.", isto é, as obras de autoria incerta ou duvidosa conhecidas pelo título resultante das muitas edições, versões ou traduções que elas tiveram no transcurso dos séculos.

A afirmação de Lehnus, de fato, é observável nas regras contemporâneas e subsequentes de Panizzi. Veja-se que Charles CoffinJewett, pioneiro estadunidense da Catalogação, deu seguimento ao entendimento do italiano sobre o cabeçalho "Bíblia". Jewett foi quem elaborou as regras conhecidas como "On the Construction of Catalogs" (1853), originalmente publicadas um ano antes. Algumas delas são cópias das "91 Regras"; outras, alteradas, outras acrescentadas e "[...] outras se conformam mais com as regras propostas pelo Sr. Panizzi do que as finalmente sancionadas pelos administradores do Museu" (LONDON apud FRÍAS MONTOYA, 1995, p. 276, tradução nossa).

No tocante ao cabeçalho "Bíblia", Jewett (1853, p. 61-62) incluiu regras específicas para a obra sagrada (regras XXV e XXXVII) com o fim de agrupar e dispor essa obra e suas partes no catálogo, sem, no entanto, realizar modificações substanciais quanto ao que Panizzi desenvolvera. A única 
alteração que ele fez se deu na posição das entradas dos livros apócrifos, as quais deviam ser ordenadas no catálogo após as partes do Novo Testamento (regra XXXVII).

Ao final do século XIX, Charles AmmiCutter ${ }^{3}$ (1837-1903), natural de Boston, nos Estados Unidos, foi outro quem deu seguimento àquilo que Maunsell realizou em catálogo e Panizzi estabeleceu em regras catalográficas. Cutter concebeu um conjunto de regras catalográficas, as "Rules for a Printed Dictionary Catalogue" (1904), as quais foram pautadas por objetivos (referidos por ele como objeto) a serem atingidos pelo catálogo modelado por suas regras flexibilizadas conforme a conveniência do usuário do catálogo.

Cutter se valeu do termo "Bíblia" na regra 123 de seu código, mas, ao contrário de Jewett, reposicionou as entradas dos livros apócrifos entre o Velho e o Novo Testamento, como fizera Panizzi. Para além disso, desdobrou outras formas de divisão do termo "Bíblia", como pode ser visto no esquema a seguir:

Figura 5: Esquemade ordenação das entradas sob "Bíblia" no "Rules for a Dictionary Catalog" (1904)

Bíblia completa

- poliglota

- línguas ordenadas alfabeticamente

obras que ilustram toda a Bíblia

seleções da Bíblia

livros proféticos da Bíblia

velho Testamento.

- obras ilustradas.

- partes do Velho Testamento, seguidas das publicações que as ilustram.

livros apócrifos.

novo Testamento.

- obras ilustradas.

- partes do Novo Testamento, seguidas das publicações que as ilustram.

Fonte: Cutter (1904, p. 57)

Dentro de cada divisão, as entradas deviam ser listadas do seguinte modo: edições com texto original ordenadas cronologicamente; versões

3 Embora Cutter proclamasse ser o primeiro pesquisadora anunciar os princípios de catalogação e o primeiro a estabelecer as regras de catalogação sistematicamente, segundo Hufford (1992, p. 31) e Hanson e Daily (1970, p. 275), suas ideias foram influenciadas direta ou indiretamente por Panizzi, Jewett, Perkins, Abbot, Poole e outros bibliotecários de seu tempo.

Inf. Inf., Londrina, v. 23, n. 2, p. 152 - 180, maio/ago. 2018. http://www.uel.br/revistas/informacao/ 
traduzidas em ordem alfabética das línguas; publicações bíblicas ilustradas. Vale mencionar que Cutter (1904, p. 57) tinha consciência de que estaria mais de acordo com os princípios de um catálogo dicionário "[...] colocar os livros separados da Bíblia sob seu próprio nome, conforme está na versão [bíblica] inglesa revista [...]". Porém, ao considerar a conveniência do usuário do catálogo, ele entendeu que o modo de formar e ordenar "Bíblia" conforme a regra 123 é o melhor para tratar as entradas das publicações relativas à Bíblia e suas partes, qualquer que seja o idioma ou título do livro sagrado.

De mais a mais, por analogia à Bíblia, Cutter incluiu a regra 124, com o fim de estabelecer o cabeçalho para outros livros sagrados, como Talmude, Avesta, Alcorão, dentre outros (1904, p. 57). Ao que parece, tal regra foi tomada das "Condensed Rule For Author and Title Catalog" (AMERICAN LIBRARY ASSOCIATION, 1883, p. 251), conjunto de regras catalográficas dessa associação criado com a participação colaborativa de diversas instituições e pessoas, dentre as quais se destacou Cutter. Seja como for, a prática de reunir edições, traduções sobre ou de uma obra sagrada sob um mesmo termo titular começou a ser expandido para outros livros sagrados, graças àquilo que já se fazia com a "Bíblia".

As regras de Cutter foram desenvolvidas, revisadas e alteradas para constituir novas regras, sobretudo na vertente anglo-americana, de maneira que as regras catalográficas desse contexto são herdeiras diretas daquilo que Cutter concebeu. Segundo Immroth e Daily (1971, p. 67), as "Catalog Rules: Author and Title Entries" (primeira edição do Código da ALA de 1908, publicada de modo conjunto com a Library Association da Grã-Bretanha) foram publicadas como uma revisão das regras de Cutter, as quais foram seguidas: das "A.L.A. Catalog Rules: Author and Title Entries" (1941), segunda edição preliminar do Código da ALA; das "A.L.A. Cataloging Rules for Author and Title Entries" - Código da ALA de 1949; das "Rules for Descriptive Cataloging in the Library of Congress" (RDC) - as quais tratam de regras de catalogação descritiva (LIBRARY OF CONGRESS, 1949); e das "Anglo-American Cataloging Rules" - código publicado em 1967. 
Com efeito, o Código da ALA de 1908 não distou substancialmente daquilo que Cutter definira em suas regras, mas a edição posterior desse conjunto de regras - Código da ALA de 1941 - quebrou a tradição de fornecer uma ordenação das entradas que considerava a ordem dos livros bíblicos na obra sagrada. No lugar disso, há orientações que permitem formar um cabeçalho pelo qual as entradas deveriam ser dispostas alfabeticamente no catálogo. Nesse âmbito, às orientações nas alíneas da regra 208 desse código, subjaz a constituição de um cabeçalho à semelhança de uma fórmula que ficou sedimentada no Código da ALA de 1949 e nos códigos posteriores. Assim, a formulação do cabeçalho da obra sagrada na regra em questão considerou esta formação:"Bíblia”. Partes bíblicas. Língua. Forma. Ano de publicação. Versão bíblica.

Nesses termos, ao cabeçalho principal "Bíblia" sucediam: suas partes as siglas em inglês O.T. ou N.T designativas de Novo e Velho Testamento, o nome do livro ou do grupo de livros, conforme o caso; a língua do texto bíblico; a indicação de forma, se fosse o caso (para cegos, concordâncias, lições litúrgicas, manuscritos, paráfrases, seleções, forma abreviada); e o título da versão bíblica, se impresso na publicação. Tudo isso ficou estabelecido na regra 34 com suas derivações (de "A" a "F") do Código da ALA de 1949, daí, é possível observar entradas como estas, exemplificadas pelo próprio Código: "Bible. English. 1611. Authorized.", "Bible. O. T. German. 1876." ou "Bible. O. T. Genesis. English. 1851." (AMERICAN LIBRARY ASSOCIATION, 1949, p. 34).

Como se vê, a última versão do Código da ALA estabeleceu uma ruptura com as regras anteriores, pois orienta ordenar alfabeticamente o cabeçalho titular "Bíblia" e seus subcabeçalhos, e não segundo a ordem das partes e livros bíblicos na escritura sagrada ou segundo um esquema de ordenação regulado em regra catalográfica.

Para além do que foi dito, cumpre ainda mencionar que o glossário do Código da ALA de 1941 incorpora e define em seu glossário o termo "título uniforme", em razão de, segundo Weihs e Howarth (2008, p. 364-365), o mesmo ter sido empregado pela comunidade catalogadora entre as versões do Código de 1908 e 1941. No entanto, a versão de 1941 valeu-se mais dos 
termos "cabeçalho uniforme", "título convencional", "título distintivo" e "título geralmente conhecido" nas orientações relativas à catalogação de clássicos anônimos, inscrições, manuscritos, incunábulos, música e obras sagradas (TILLETT, 1992, p. 31). Nesse âmbito, o problema é que somente o "título convencional" foi definido no glossário desse conjunto de regras como equivalente de título uniforme; os outros, ficaram sem definição e sem associação expressa com o título uniforme. A despeito disso, é possível perceber que esse termo começou a ser expandido e associado em regras catalográficas às situações bibliográficas das publicações mencionadas acima.

Enquanto isso, nas décadas de 1940 e 1950, a Catalogação passava por um momento de crise quanto aos objetivos e aos princípios das regras catalográficas. O clímax dessas discussões se deu na "Conferência Internacional sobre Princípios de Catalogação", evento realizado em Paris - em outubro de 1961. Na oportunidade, foi a aprovada pelos participantes do evento a "Declaração dos Princípios da Catalogação", algo como uma base normativa de uma catalogação colaborativa em nível internacional.

Da declaração, importa destacar a parte relativa às duas funções que 0 catálogo da biblioteca deve desempenhar, funções pertinentes à discussão do cabeçalho "Bíblia" (INTERNATIONAL CONFERENCE ON CATALOGUING PRINCIPLES, 1963, p. 91-92): 1) revelar se a biblioteca possui um determinado livro especificado por autor e por título ou, se inadequados, por um substituto; 2) revelar as obras de determinado autor e as edições de uma determinada obra existentes na biblioteca. Boa parte das discussões sobre o catálogo girou em torno dessas funções, posto que a primeira função se refere a unidades bibliográficas - representar publicações específicas; a segunda, a unidades literárias - representar edições e traduções de uma obra.

No tocante ao cabeçalho "Bíblia", a "Declaração..." não tece detalhes sobre isso, mas é possível constatar que ele foi discutido durante a conferência sob o conceito de cabeçalho uniforme (forma específica do nome do autor ou de um título em particular, seção 11.3 da declaração), conforme sinalizou Verona (1971) ao comentar o texto da declaração. Veja-se que Eisenhart (1963, p. 206) tratou do tema num dos artigos apresentados na Conferência, no 
qual ela chama a atenção dos catalogadores para a formação de subcabeçalhos alusivos aos livros bíblicos, posto que: há diferenças entre livros bíblicos católicos e protestantes, pois estes têm menos livros do que aqueles em seus respectivos cânones; e há diferenças dos nomes bíblicos conforme a versão bíblica padrão adotada dentro e no entorno dos segmentos da cristandade. A despeito dessas questões, o entendimento fundamental sobre a concepção desse cabeçalho não foi alterado substancialmente quanto àquilo que já se praticava por intermédio do Código da ALA de 1949, conforme salientou Pierrot (1963, p. 187-188) em seu artigo, também apresentado na Conferência.

Após a Conferência, o AACR publicado em 1967 foi o conjunto de regras que sucedeu às regras da ALA de 1949. No que respeita ao cabeçalho "Bíblia", - AACR desenvolveu a concepção do título uniforme e, pela primeira vez, emprega expressamente o termo "título uniforme" associado ao cabeçalho "Bíblia" entre as regras 108 e 114 (AMERICAN LIBRARY ASSOCIATION et al., 1970, p. 156).

O código de 1967 manteve a inscrição de subcabeçalhos à semelhança da fórmula subjacente ao Código da ALA de 1949, de modo a designar partes, língua, versão ou ano de publicação da Bíblia, mas retira o subcabeçalho forma. Ademais, o AACR altera a ordem do ano de publicação, posicionando-o como último elemento de formação dos subcabeçalhos, contrariamente ao Código da ALA de 1949, que coloca a versão como último elemento. A propósito, os reposicionamentos, as adições, as retiradas e outros ajustes são observáveis no quadro comparativo a seguir.

Figura 6: Comparativo da ordem dos elementos do subcabeçalho de "Bíblia", com exemplos dos códigos da ALA e do AACR e suas revisões subsequentes

CÓDIGO DA ALA (1949)

\begin{tabular}{|c|c|c|c|c|c|c|}
\hline \multicolumn{7}{|c|}{ CABEÇALHO } \\
\hline principal & \multicolumn{6}{|c|}{ subcabeçalhos } \\
\hline \multirow{3}{*}{ Bíblia. } & \multicolumn{2}{|c|}{ partes } & \multirow{3}{*}{ língua. } & \multirow{3}{*}{$\begin{array}{c}\text { ano de } \\
\text { publicação. }\end{array}$} & \multirow{3}{*}{ forma } & \multirow{3}{*}{ versão. } \\
\hline & \multirow{2}{*}{ testamento. } & livro. & & & & \\
\hline & & grupos de livros. & & & & \\
\hline
\end{tabular}

Exemplos:

Bible. English. 1611. Authorized.

Bible. O. T. Genesis. English. 1851. 
Figura 6: Comparativo da ordem dos elementos do subcabeçalho de "Bíblia", com exemplos dos códigos da ALA e do AACR e suas revisões subsequentes

\begin{tabular}{|c|c|c|c|c|c|c|}
\hline \multicolumn{7}{|c|}{ AACR (1967) } \\
\hline \multicolumn{7}{|c|}{ CABEÇALHO } \\
\hline principal & & & subca & calhos & & \\
\hline \multirow[b]{2}{*}{ Bíblia. } & & partes & \multirow[b]{2}{*}{ seleções. } & \multirow[b]{2}{*}{ língua. } & \multirow[b]{2}{*}{ versão. } & \multirow[b]{2}{*}{$\begin{array}{c}\text { ano de } \\
\text { publicação. }\end{array}$} \\
\hline & testamento. & $\begin{array}{c}\text { livro. } \\
\text { grupos de livros. }\end{array}$ & & & & \\
\hline
\end{tabular}

Exemplos:

Bible. Spanish. Torres Amat. 1871.

Bible. Catholicepistles...

AACR2 (1978) E SUAS REVISÕES (1988, 1998 e 2002)

\begin{tabular}{|c|c|c|c|c|c|c|}
\hline \multicolumn{7}{|c|}{ CABEÇALHO } \\
\hline principal & \multicolumn{6}{|c|}{ subcabeçalhos } \\
\hline \multirow{3}{*}{ Bíblia. } & & partes & & \multirow{3}{*}{ língua. } & \multirow{3}{*}{ versão. } & \multirow{3}{*}{$\begin{array}{c}\text { ano de } \\
\text { publicação. }\end{array}$} \\
\hline & \multirow{2}{*}{ testamento. } & livro. & seleções. & & & \\
\hline & & grupos de livros. & excertos. & & & \\
\hline
\end{tabular}

Exemplos:

Bíblia. A.T. Gênesis XII, l-XXV, 11 ...

Bíblia. Espanhol. Torres Amat. 1871.

Bíblia. N.T. Livros apócrifos.

Fontes: "A.L.A. Cataloging Rules for Author And Title Entries" (AMERICAN LIBRARY ASSOCIATION, 1949, regra 34), "Anglo-American Cataloging Rules" (AMERICAN LIBRARY ASSOCIATION et al. 1970) e Código de catalogação anglo-americano (JOINT STEERING COMMITTEE FOR REVISION OF AACR, 2004).

Desde o Código da ALA de 1949, como se observa na figura acima, a compreensão e a fórmula do cabeçalho "Bíblia" como título uniforme é uma prescrição presente na edição e nas revisões subsequentes desse código e do AACR, inclusive sua segunda edição de 1978 (conhecida pela sigla AACR2), e suas revisões de 1988, de 1998 e de 2002 (referidas como AACR2R). Nesses termos, é notório que o título uniforme foi adotado por muitos catalogadores para reunir as entradas das edições e traduções e outras publicações da Bíblia, ainda que sua aplicação fosse facultativa segundo a Regra 25.1 do AACR2, o que tornava o título uniforme como uma espécie de elemento 'adormecido' do AACR2, qualificam Weins e Howarth (2008, p. 379). A despeito dessa sonolência, o valor do título uniforme como representativo dos atributos da unidade literária que no conjunto a singularizam deveria ser suficiente para fundamentar sua aplicação.

Nesse âmbito, porém, há problemas quanto à composição do título uniforme por intermédio do AACR2, pois certos elementos constitutivos desse 
título para a "Bíblia" não são atributos próprios dessa unidade literária, posto que dizem respeito às suas unidades bibliográficas: língua, versão e ano de publicação. Desse modo o acréscimo do ano de publicação, por exemplo, acaba por cooperar com a identificação de uma edição específica da obra sagrada, por isso Delsey (1999, p. 84, tradução nossa) questionava "[...] a racionalidade subjacente a regras que associam elementos relacionados a uma edição específica de uma obra com a identidade dela em si [...]".

Buscando resolver essas e outras incoerências em catalogação, três modelos bibliográficos foram concebidos sob a técnica de análise entidaderelacionamento (E-R) de Peter Chen, os quais buscam propor uma compreensão conceitual do universo bibliográfico mais apropriada para a catalogação: o primeiro, "Requirements for Bibliographic Records" (FRBR) ${ }^{4}$, foi publicado em 1998; os "Functional Requirements for Authority Data" (FRAD)", em 2009; e os "Functional Requirements for Subject Authority Data" (FRSAD), em 2010 - todos referidos como família dos FRBR.

Pela técnica $E-R$, os criadores dos FRBR conceberam onze entidades, as quais são entendidas no modelo como qualquer coisa ou objeto que pode ser analisado e identificado de forma particular, especialmente por seus atributos, que são as propriedades que caracterizam a entidade. Por sua parte, relacionamento é uma associação formada por meio de duas ou mais entidades, meio importante para que o usuário formule buscas bibliográficas, interprete respostas relativamente às suas pesquisas e 'navegue' pelo universo de entidades descritas no registro bibliográfico (INTERNATIONAL FEDERATION OF LIBRARY ASSOCIATIONS AND INSTITUTIONS, 2009a).

Com esse direcionamento, esses Modelos - sobretudo os FRBR e os FRAD - têm se mostrado mais fundamentados que o modelo subjacente ao texto do AACR2, sobretudo quanto à distinção das entidades bibliográficas do processo catalográfico, dentre as quais importa destacar a obra, entidade

\footnotetext{
4 "Requisitos FuncionaisdosRegistros Bibliográficos", publicados pela IFLA (2009a).

5 "Requisitos Funcionais para Dados de Autoridade", publicados pela IFLA (2009b).

6 "Requisitos Funcionais para Dados de Autoridade de Assunto", publicados pela IFLA (2010).
} 
passível de ter título uniforme, e expressão, que é o meio pelo qual os sentidos humanos apreendem ou percebem a obra.

Tendo esses modelos como base, a normativa "Resource Description and Access" (RDA) foi publicada pela Joint Steering Committee for Development of RDA (2011) para substituir o AACR2R. No âmbito dela, o termo "título uniforme" foi substituído por 'título preferido', que nos FRBR é o atributo 'título da obra'. Em face disso, ao se observar a regra da normativa que trata de "Bíblia" (regra 6.23.2.9), a atribuição do título preferido que representa a obra sagrada em ponto de acesso deve considerar tão somente os atributos da Bíblia, ficando os demais por conta de outra entidade (expressão), como se nota nesta figura.

Figura 7: Elementos e exemplos para constituir o ponto de acesso autorizado para a Bíblia na normativa RDA

\begin{tabular}{|c|c|c|c|c|c|}
\hline \multicolumn{6}{|c|}{ PONTO DE ACESSO AUTORIZADO PARA BÍBLIA } \\
\hline \multicolumn{3}{|c|}{$\begin{array}{c}\text { OBRA } \\
\text { TíTULO PREFERIDO DE OBRAS SAGRADAS } \\
(6.23 .2) \\
\end{array}$} & \multirow{2}{*}{\multicolumn{3}{|c|}{ EXPRESSÃO (6.30.3.2) }} \\
\hline $\begin{array}{c}\text { obra sagrada } \\
(6.23 .2 .5)\end{array}$ & \multicolumn{2}{|c|}{ partes bíblicas (6.23.2.9) } & & & \\
\hline \multirow{3}{*}{ Bíblia. } & & mento. & \multirow{3}{*}{$\begin{aligned} \text { língua } \\
(6.11)\end{aligned}$} & \multirow{3}{*}{$\begin{array}{l}\text { versão. } \\
(6.25 .1 .4)\end{array}$} & \multirow{3}{*}{$\begin{array}{l}\text { data. } \\
(6.24 .1 .4)\end{array}$} \\
\hline & $\begin{array}{l}\text { livro } \\
\text { bíblico. }\end{array}$ & $\begin{array}{l}\text { partes do livro } \\
\text { bíblico. }\end{array}$ & & & \\
\hline & \multicolumn{2}{|c|}{ grupos de livros bíblicos. } & & & \\
\hline
\end{tabular}

Exemplos:

Novo Testamento. Português. Nova Tradução na Linguagem de Hoje. Bíblia. 2000.

Bible. Samuel, 2nd...

Bible. Gospels. English. Revised Standard. 1975

Fonte: "Joint Steering Committee for Development of RDA" (2011).

Nota: indica-se entre parêntesis estão indicadas as regras que orientam a formação de um dado elemento RDA.

Como se nota, o título preferido é composto pelos atributos da unidade literária - título da obra e suas partes - e não comporta indicações de língua, de versão e de ano de publicação, os quais são atributos da expressão da obra e são acrescidos por ocasião da composição do ponto de acesso autorizado. Com tal composição, nos termos da normativa RDA, o título preferido para a obra sagrada, de fato, representa a "Bíblia", independentemente de sua 
expressão, manifestação ou item, e o mesmo vale para as partes ou divisões bíblicas.

A ressalva disso, no entanto, deve ser feita quando se considera as diferenças do texto da Bíblia cristã e da judaica, uma vez que esta não divide a obra em Novo e Velho Testamento, de sorte que as entradas sob a Bíblia cristã são inapropriadas de serem aplicadas na Bíblia judaica. Daí, não podem ser tratadas do mesmo modo, conforme sinaliza Conners (2009), o qual propõe soluções de título uniforme que contempla as Bíblias judaica e cristã.

A despeito de ressalvas como essa, é inegável que o advento dos modelos FRBR e da normativa RDA conseguiu reduzir substancialmente as incoerências que havia no cabeçalho titular modelado pelo AACR2, ao promover a concepção de um título preferido constituído dos atributos representativos e identificadores da obra sagrada, o qual a representa em sua totalidade ou em suas partes.

Ante ao que se expôs nesta seção, constata-se que a contribuição de Maunsell no tocante ao cabeçalho titular "Bíblia" foi apropriada pela Catalogação, conforme sinalizam estudiosos dessa área, ainda que por aproximação, por coocorrência, por similaridade ou mesmo por influência direta ou não. No transcurso dos anos, esse cabeçalho vem sendo trabalhado e retrabalhado na prática catalográfica, ao qual foram adicionados subcabeçalhos alusivos aos atributos da obra sagrada. Ao mesmo tempo, o modo de dispor subcabeçalhos se deu com avanços e reveses, tendo em conta que por vezes alguns deles foram incluídos, retirados, posicionados e reposicionados no cabeçalho. No estágio atual, o cabeçalho e os subcabeçalhos foram tratados nos termos dos modelos FRBR e da normativa RDA, de modo que o mesmo se mostra mais coerente comparativamente ao que havia antes, pois cada atributo subjacente ao cabeçalho e às suas partes é tratado metodologicamente nesses modelos e normativas.

\section{CONSIDERAÇÕES FINAIS}

Em face do exposto, temos evidenciado como as contribuições provenientes de Andrew Maunsell, produzidas originalmente num contexto 
histórico de um mercado livreiro britânico em formação, se assentaram nos catálogos e nas regras catalográficas da vertente anglo-americana. Naquele momento, o londrino serviu-se de soluções para dispor as entradas em seu catálogo mediante o uso de pontos de acesso marcados em itálico nas entradas ou nos cabeçalhos sobre elas, os quais, além do assunto, podia ser designativo: do sobrenome do autor da publicação; do cabeçalho titular com função agrupadora de publicações relativas à Bíblia; do título da publicação, se obra anônima; e do sobrenome do tradutor, se presente na publicação.

Valeria explorar cada uma delas, de modo a examinar como elas foram apropriadas pela Catalogação no transcurso dos anos e como concorreram substancialmente à feição dos cabeçalhos de entrada como os temos hoje nos pontos de acessos autorizados. Porém, foi necessário destacar o cabeçalho "Bíblia" de modo a examiná-la como um exemplo daquilo que foi efetivado nos catálogos de bibliotecas posteriormente.

Para tanto, valemo-nos dos momentos históricos significativos da catalogação anglo-americana, pelos quais se pôde observar que a catalogação foi incorporando subcabeçalhos alusivos aos atributos da obra sagrada. Os subcabeçalhos, pospostos ao termo "Bíblia", eram acrescidos com o fim de representar e identificar essa obra em sua totalidade, em suas partes ou em algum de seus aspectos. Nesses termos, os efeitos dos subcabeçalhos no arranjo das entradas incidiam em duas dimensões ao menos: uma vertical, que diz respeito ao arranjo dos subcabeçalhos no catálogo; outra horizontal, relativa ao que se apresenta nos segmentos dos elementos delimitadores do cabeçalho principal e à precedência dos mesmos.

Porém, isso nem sempre se deu coerentemente, posto que - em dimensão vertical - as entradas com subcabeçalho representativo das partes e dos livros bíblicos eram dispostas no catálogo conforme a ordem destes na obra sagrada ou ao sabor de quem idealizara o conjunto de regras catalográficas. Isso perdurou até o Código da ALA de 1908, já que as entradas com subcabeçalhos das partes bíblicas passaram a ser dispostas alfabeticamente nas versões que sucederam a esse código. 
Em dimensão horizontal, houve hesitação quanto à inclusão e precedência dos subcabeçalhos alusivos aos atributos da obra sagrada e ao modo de dispor suas partes e divisões, tendo em conta que por vezes foram incluídos, retirados, posicionados e reposicionados no cabeçalho. Em algumas situações, tais hesitações se deram em razão das diferenças de entendimento que há entre as versões bíblicas dentro e fora de cada segmento religioso do Cristianismo e mesmo do Judaísmo. Em outras situações, porém, as incoerências ocorreram em razão de os subcabeçalhos conterem atributos que não diziam respeito diretamente à unidade literária em questão.

Em grande medida, os recentes modelos FRBR e a normativa RDA foram concebidos para reduzir tais inconsistências, de sorte que, nos termos da obra sagrada, eles conseguem dar conta de representar singularmente essa unidade literária, a despeito das ressalvas contornáveis que possam haver.

Para além disso, não se pode esquecer que, a partir do cabeçalho titular "Bíblia", a catalogação desenvolveu o fundamento e os princípios do título uniforme enquanto representativo dos atributos da unidade literária que subjaz às publicações de outras obras sagradas; às publicações com clássicos anônimos, às publicações com música dentre outras.

Tudo isso é legado das ideias de um livreiro londrino, o qual, na condição de bibliógrafo pioneiro, compilou uma bibliografia de alcance nacional, na qual ele se valeu de procedimentos que perduram ainda hoje na catalogação. Desse modo, Maunsell é preconizador das práticas catalográficas anglo-americana, muitas das quais igualmente empregadas em várias partes do mundo, inclusive no Brasil. Por isso, convém sublinhar e parafrasear a obra sagrada e afirmar que "ele plantou; outros regaram".

\section{REFERÊNCIAS}

AMERICAN LIBRARY ASSOCIATION et al. Anglo-American Cataloging

Rules. Chicago: American Library Association, 1970. 
AMERICAN LIBRARY ASSOCIATION. Catalog Code Revision Committee. A.L.A. Catalog Rules: author and title entries. Preliminary American 2. ed. Chicago, III.: American Library Association, 1941. Disponível em: $<$ https://ia600204.us.archive.org/19/items/lacatalogrulesau 007893mbp/lacatalogrulesau007893mbp.pdf>. Acesso em: 11 ago. 2016.

Cooperation Committee. Condensed Rules for an Author and Title Catalog. Library Journal, v. 8, p. 251-254, jan./dez. 1883. Disponível em: <http://hdl.handle.net/2027/njp.32101076204948>. Acesso em: 30 jul. 2016.

AMERICAN LIBRARY ASSOCIATION. Division of Cataloging and Classification. A.L.A. Cataloging Rules for Author and Title Entries. 2. ed. Chicago: American Library Assn., 1949. Disponível em: <http://archive.org/details/universallibrary>. Acesso em: 19 jul. 2012.

BISWAS, S.; RATH, D. From Maunsell to Lubetzky. Annals of Library and Information Studies (ALIS), New Delhi, v. 61, n. 1, p. 7-14, mar. 2014. Disponível em: <http://op.niscair.res.in/ index.php/ALIS/articleview/2454/94>. Acesso em: 29 jul. 2016.

BODLEIAN LIBRARY.

CatalogusImpressorumLibrorumBibliothecaeBodleianae In Academiaoxoniensi. Oxonii. [S.I.]: E theatroSheldoniano, 1738. v. 2 Disponível em: <https://books.google.com.br/books?id=JhBaAAAAYAAJ\&hl=ptBR\&pg=PP9\#v=onepage\&q\&f=false $>$. Acesso em: 18 nov. 2017.

BRITISH MUSEUM. Dept. of Printed Books. Catalogue of Printed Books In the British Museum: London: Printed by order of the Trustees, 1841. v. 1. Disponível em: <https:// books.google.com.br/books?id=OThAAAAAYAAJ\&hl=pt$B R \& p g=P R 1 \# v=0 n e p a g e \& q \& f=$ false $>$. Acesso em: 4 jul. 2017.

CATALOG RULES: author and title entries. Compiled by Committees of the American Library Association and the (British) Library Association. American Ed.Chicago: America Library Association, 1908. Disponível em: <http://archive.org/details/universallibrary>. Acesso em: 19 jul. 2012.

CONNERS, David. A "Mind-Boggling" Implication: The Hebrew Bible, the Old Testament, and the Definition of a Work. Judaica Librarianship, v. 15, p. 1-12. 2009. Disponível em: <http://dx.doi.org/10.14263/2330-2976.1049>. Acesso em: 29 out. 2015.

CUTTER, C. A. Rules for a dictionary catalog. 4. ed. Washington: Government Priting Office, 1904. Disponível em: <http://digital.library.unt.edu/ark:/67531/ metadc1048/>. Acesso: 15 abr. 2013.

DELSEY, T. The Logical Structure of the Anglo-American Cataloguing Rules - Part II. [S.I.: s.n.], 1999. Disponível em: <http://www.rdajsc.org/archivedsite/docs/aacr2.pdf>. Acesso em: 2 ago. 2017. 
EISENHART, R. Cataloguing of liturgies and religious texts in the alphabetical catalogue. In: International Conference on Cataloguing Principles, 1961, Paris. Report. London: Clive Bingley: IFLA, 1963. p. 199-206.

FRÍAS MONTOYA, J. A. La descripción bibliográfica y sus puntos de acceso en el catálogo de la biblioteca. 1995. 299 f. Tese (Doutorado) -, Facultad de Filología, Departamento de Filología Española IV, Madrid, 1995. Disponível em: < http://eprints.ucm.es/3827/1/AH3002201.pdf>. Acesso em: 4 jul. 2012.

\section{GROWOLL, A.; EAMES, W. Three Centuries of English Booktrade}

Bibliography. New York: Published for the Dibdin Club by M.L. Greenhalgh, 1903. Disponível em: <https://archive.org/details/threecenturiese00 eamegoog >. Acesso em: 8 nov. 2017.

HANSON, E. R.; DAILY, J. E. Catalogs and cataloging. In: KENT, A.; LANCOUR, $\mathrm{H}$. (Ed.). Encyclopedia of library and information science. New York: M. Dekker, 1970. p. 242-305. v. 4.

HUFFORD, J. R. The pragmatic basis of catalog codes: has the user been ignored? Cataloging \& classification quarterly, v. 14, n. 1, p. 27-38, 1992.

IMMROTH, J. P.; DAILY, J. E. Library Cataloging. Metuchen, N.J.: Scarecrow Press, 1971.

INTERNATIONAL CONFERENCE ON CATALOGUING PRINCIPLES, 1961. Paris: Report. London: Clive Bingley: IFLA, c1963.

INTERNATIONAL FEDERATION OF LIBRARY ASSOCIATIONS AND INSTITUTIONS. Study Group on the Functional Requirements for Bibliographic Records. Functional Requirements For Bibliographic Records: final report. [München]: K. G. Saur: IFLA, 2009

INTERNATIONAL FEDERATION OF LIBRARY ASSOCIATIONS AND INSTITUTIONS. Working Group on Functional Requirements and Numbering of Authority Records (FRANAR). Requisitos Funcionales de los Datos de Autoridad (FRAD): Un modelo conceptual. [Madrid]: BibliotecaNacional de España, 2009

INTERNATIONAL FEDERATION OF LIBRARY ASSOCIATIONS AND INSTITUTIONS. Functional Requirements for Subject Authority Data (FRSAD): a conceptual model. Editors: Marcia Lei Zeng, MajaŽumer, Athena Salaba. [S.I.]: IFLA, 2010. 
JEWETT, C. C. Smithsonian report on the construction of catalogues of libraries, and their publication by means of separate, stereotyped titles, with rules and examples. 2. ed. Washington: Smithsonian Institution, 1853. Disponível em: <https:// books.google.com.br/books?id=zCIDAAAAYAAJ\&hl=pt-BR>. Acesso em: 13 ago. 2016.

JOINT STEERING COMMITTEE FOR REVISION OF AACR. Código de catalogação anglo-americano. São Paulo: FEBAB, 2004.

JOINT STEERING COMMITTEE FOR DEVELOPMENT OF RDA, AMERICAN LIBRARY ASSOCIATION et al. RDA: resource description \& acess. Chicago: American Library Association, 2011.

LEHNUS, D. J. A Comparison of Panizzi's 91 Rules and the AACR of 1967. Champaign, II.: University of Illinois, Graduate School of Library Service, 1972. (Occasional Paper, n. 105). Large-scale Digitization Project, 2007.

LÓPEZ GUILLAMÓN, Ignacio. De la "notitialibrorum" a los metadatos: itinerario de la teoría sobre catalogación bibliográfica. 2011. $1030 \mathrm{f}$. Tese (Doutorado) - Universidad de Extremadura, Departamento de Información y Comunicación, Badajoz, 2011. Disponível em:

<http://hdl.handle.net/10662/314>. Acesso em: 5 out. 2016.

MALCLÈS, L. N. Bibliography. New York: The Scarecrow Press, 1961.

MAUNSELL, A. The Catalogue of English Printed Books. London: Gregg Press, 1595. pt. 1-2. Disponível em:

$<$ https://books.google.com.br/books?id=zoAeZ4bMf8oC\&hl=pt-

$B R \& p g=P P 7 \# v=0$ enepage\&q\&=false $>$. Acesso em: 23 maio 2017.

NORRIS, D. M. A history of cataloguing and cataloguing methods, $1100-$ 1850: with an introductory survey of ancient times. London: Graftom \& Co., 1939.

PETTEE, J. The development of authorship entry and the formulation of authorship rules as found in the Anglo-American code. The Library Quarterly, v. 6, n. 3, p. 270-290, jul. 1936.

PIERROT, R. Entry of anonymous works under standard of form titles. In: International Conference on Cataloguing Principles, 1961, Paris. Report. London: Clive Bingley : IFLA, c1963. p. 187-188.

REITZ, J. M. Online Dictionary for Library and Information Science. Santa Barbara, CA: ABC-CLIO, LLC, c2017. Disponível em: <http://www.abcclio.com/ODLIS/odlis_e.aspx>. Acesso em: 8 mar. 2017.

RIOS HILÁRIO, A. B. Nuevos horizontes en el análisis de los registros y la normativa bibliográfica. Gijón: Trea, 2003. 
STROUT, R. F. The development of the catalog and cataloging codes. The Library Quarterly, v. 26, n. 4, p. 254-275, out. 1956.

THE LIBRARY OF CONGRESS. Descriptive Cataloging Division. Rules for descriptive cataloging in the Library of Congress. Washington, 1949.

Disponível em: <https://catalog. hathitrust.org/Record/001162924>. Acesso em: 22 jul. 2016.

TILLETT, B. B. The history of linking devices. Library resources \& technical services, v. 36, n. 1, p. 23-36, jan. 1992. Disponível em:

<https://archive.org/details//rtsv36no1>. Acesso em: 30 mar. 2016.

VERONA, E. Literary unit versus bibliographical unit. Libri, v. 9, n. 1/4, p. 79104, jan. 1959.

VERONA, E. Statement of principles: adopted at the International Conference on Cataloging Principles, Paris, October, 1961. London: IFLA Committee on Cataloguing, 1971.

WEIHS, J.; HOWARTH, L. C. Uniform titles from AACR to RDA. Cataloging \& classification quarterly, v. 46, n. 4, p. 362-384, 2008.

\title{
CONTRIBUTIONS BY ANDREW MAUNSELL TO THE CATALOGING: A BRIEF STORY OF THE HEADING "BIBLE"
}

\begin{abstract}
Introduction: Andrew Maunsell's contributions have influenced the design of access points to catalog entries over the years since many of them is still in catalogs and in the Anglo-American cataloging rules such as the heading "Bible" used to gather the entries of this work in the catalog. Objective: To draw the historical context of the Londoner bookseller in order to know how he idealized the heading and how he used it in his time; and to exam historically how the heading "Bible" has been used in catalogs and later cataloging rules in order to investigate how the cataloging has appropriated that heading for representing the sacred work. Methodology: Bibliographic and documentary research. Results: The research finds that the cataloging has incorporated subheadings allusive to the attributes of the sacred work, which influenced the arrangement of the entries that work in vertical and horizontal dimension. Moreover, by the heading "Bible", the cataloging was able to develop the groundwork and principles of uniform title to represent other works. But this has not always been done consistently because the uniform title has been unstructured by subheadings unrelated to the representation of the sacred work. In the face of the incoherence, the bibliographic models and the "Resource Description and Access" (RDA) were designed to reduce improprieties in cataloging such as the case of that subheadings. Conclusions: Despite the fact that there are some objections, the RDA is able to represent the Bible in the access points of the bibliographic records that refer
\end{abstract}

Inf. Inf., Londrina, v. 23, n. 2, p. 152 - 180, maio/ago. 2018.

http://www.uel.br/revistas/informacao/ 
to publications of that sacred work. Therefore, Maunsell planted cataloging practices that were watered by those who developed cataloging over the time.

Descriptors:Maunsell, Andrew, ?-1596. Entries. Cataloging rules.

\title{
CONTRIBUCIONES DE ANDREW MAUNSELL A LA CATALOGACIÓN: NARRA-TIVA BREVE DEL ENCABEZAMIENTO "BIBLIA"
}

\begin{abstract}
RESUMEN
Introducción: Las contribuciones de Andrew Maunsellhan influenciado la concepción de los puntos de acceso a las entradas de los catálogos bibliotecarios al transcurso del tiempo, ya que muchas de ellas todavía están en catálogos y en las reglas de catalogación anglo-americanas, como es el caso del encabezado titular "Biblia", empleado para reunir las entradas de esa obra en el catálogo. Objetivo: Exponer el contexto histórico del librero londinense, con el fin de conocer cómo ideó el encabezamiento y cómo lo empleó en su tiempo; examinar históricamente cómo el encabezamiento "Biblia" se efectuó en los catálogos y enlasreglas catalográficas posteriores, para investigar cómo la catalogación se ha apropiado de ese encabezamiento para representar la obra sagrada. Metodología: Se realizó un estudio bibliográfico y documental.Resultados: La catalogación ha incorporado subencabezamientos alusivos a los atributos de la obra sagrada, los cuales influenciaron la disposición de sus entradas en dimensión vertical y horizontal. Además, por el encabezamiento "Biblia", la catalogación ha podido desarrollar el fundamento deltitulo uniforme para representar otras obras. Pero, laefectividaddeltitulo uniforme no se dió por completo porque él fue desestructurado por subencabezamientos extraños a la representación de la obra sagrada. Frente a la situación, modelos bibliográficos de la catalogación y la normativa "ResourceDescriptionand Access" (RDA) fueron diseñados para reducir las impropiedades de la catalogación, como las que hay en los subencabezamientos de la obra sagrada. Conclusiones: La normativa RDA ofrece medios de representar la Biblia en los puntos de acceso de los registros bibliográficos de las publicaciones de dicha obra, a pesar de una u otra limitación. Así, Maunsellplantóprácticas catalográficas que fueron regadas por aquellos que desarrollaron la catalogación en el transcurso de los años.
\end{abstract}

Descriptores:Maunsell, Andrew, ?-1596. Entradas. Reglas de catalogación.

Recebido: 10.05 .2018

Aceito: 25.08.2018

Inf. Inf., Londrina, v. 23, n. 2, p. 152 - 180, maio/ago. 2018

http://www.uel.br/revistas/informacao/ 